\title{
Serum Copeptin Level and High-Sensitivity C-Reactive Protein in Centrally Obese Middle-Aged Male Subjects
}

\author{
Kyi Kyi Myintt ${ }^{1,2}$, Aung Khaing ${ }^{1}$, Mya Mya Thwin ${ }^{1,3, *}$
}

Kyi Kyi Myint ${ }^{1,2}$, Aung

Khaing ${ }^{1}$, Mya Mya

Thwin ${ }^{1,3, *}$

'Department of Physiology, University of Medicine 2, Yangon, MYANMAR.

${ }^{2}$ Department of Physiology, University

of Medicine Magway, Magway,

MYANMAR.

${ }^{3}$ Physiology Unit, University Sultan Zanial Abidin, Kuala Terengganu, Terengganu, MALAYSIA.

\section{*Correspondence}

\section{Dr. Mya Mya Thwin}

${ }^{1}$ Former Professor and Head of Department of Physiology, University of Medicine 2, Yangon, MYANMAR.

${ }^{3}$ Associate Professor, Physiology Unit, University Sultan Zanial Abidin, Kuala Terengganu, Terengganu, MALAYSIA.

Phone: +60102394366

Email: drmyamyathwin2011@gmail. com

\section{History}

- Submission Date: 02-01-2021;

- Review completed: 17-03-2021;

- Accepted Date: 25-03-2021.

DOI : 10.5530/ijcep.2021.8.1.6

Article Available online

http://www.ijcep.org

\section{Copyright}

(C) 2021 Phcog.Net. This is an openaccess article distributed under the terms of the Creative Commons Attribution 4.0 International license.

\begin{abstract}
Background and Aim: Copeptin, a surrogate marker of Arginine Vasopressin, has been recently used as stress related neuroendocrine marker. In addition, chronic psychosocial stress had an association with increased inflammatory cytokines. Moreover, obesity has been recognized as high inflammatory status. Thus, it has been generated an interest whether centrally obese with high copeptin level have higher inflammatory status comparing to those with low copeptin level or not. Methods: Eighty-seven centrally obese male subjects between 40-60 years were recruited for this study. Anthropometric measurements such as height, weight, BMI and waist circumference were measured. Blood sample was collected to measure copeptin and hsCRP. Results: 29 subjects (33.33\%) had low copeptin level $(<5 \mathrm{pmol} / \mathrm{L})$ and 58 subjects $(66.67 \%)$ had high copeptin level ( $\geq 5 \mathrm{pmol} / \mathrm{L})$. Median hs-CRP levels were $2.86 \mathrm{mg} / \mathrm{L}$ (IQR: 1.63-6.7) and $3.42 \mathrm{mg} / \mathrm{L}$ (IQR: 2.44-5.46) in obese with low copeptin level and obese with high copeptin level respectively. There was no significant difference in hs-CRP levels between these two study groups $(p=0.7)$. Conclusion: In the study population of the present study, there was no correlation found between copeptin and inflammatory status.

Key words: Copeptin, Stress, Inflammatory status, Obese, hsCRP.
\end{abstract}

\section{INTRODUCTION}

Coeptin, a surrogate marker of vasopressin, is carboxy-terminal fragment of the pre-pro-hormone arginine vasopressin (AVP) and so it is co-secreted with AVP in equal molar amount. ${ }^{[1]}$ Pre-pro-AVP is synthesized in magnocellular hypothalamic neurons of supraoptic (SON) and paraventricular (PVN) nuclei and then packaged into neurosecretory granules. During axonal transport to the posterior pituitary, Pre-pro-AVP is cleaved into the product peptides: AVP, neurophysin II and copeptin. All three peptides are released from the posterior pituitary after hemodynamic or osmotic stimuli. ${ }^{[1]}$ Thus, copeptin has a potential role in diagnosis and prognosis of various diseases. ${ }^{[2]}$

In addition, AVP is also synthesized by parvicellular neurons of the paraventricular nucleus and is secreted into the pituitary portal circulation via axon terminals projecting to the external zone of the median eminence. Then, AVP enters the adenohypophyseal circulation and acts as a corticotropin releasing factor at the anterior pituitary. Therefore, the number of AVP-expressing cells increases substantially during chronic stress and pituitary ACTH responsiveness to novel stress subsequently increases. In rat colonies, chronic psychosocial stress increased AVP synthesis in parvicellular neurons in the paraventricular nucleus. ${ }^{[3]}$ In a study, caregivers suffering from chronic stress revealed average higher level of

Cite this article: Myint KK, Khaing A, Thwin MM. Serum Copeptin Level and High-Sensitivity C-Reactive Protein in Centrally Obese Middle-Aged Male Subjects. Int J Clin Exp Physiol. $2021 ; 8(1): 22-5$. copeptin compared to control. ${ }^{[4]}$ But, until now, there had been few studies using copeptin as chronic stress biomarker. Chronic stress also associated with increase in inflammatory markers such C-reactive protein, IL-6 and TNF- $a^{[5]}$ The present study measured the copeptin level among centrally obese subjects and compared the inflammatory status of high copeptin participants with that of low copeptin participants.

\section{MATERIALS AND METHODS}

The study was approved by the Ethics Review Committee 3 on Medical Research involving human subjects, University of Medicine 2, Yangon. The study was started in June, 2017. Centrally obese male subjects between 40-60 years were recruited for this study. All participants were given written informed consent prior to inclusion in the study. Because the study was aimed to measure copeptin as neuroendocrine marker for chronic stress, persons having current major stressful life events, taking drugs which affect AVP system (exogenous vasopressin, vasopressin receptor antagonists) and drugs which has effect on blood volume and osmolality (diuretics) were excluded. Height and weight were measured for the recruited 87 participants and then their BMI was calculated. Then, $6 \mathrm{ml}$ of venous blood was taken. 
The blood samples were allowed to clot for $30 \mathrm{~min}$ then centrifuged approximately $1000 \mathrm{x} \mathrm{g}$ for serum separation. Then, the serum was made into two aliquots (one aliquot for measurement of copeptin and another one for measurement of hsCRP) and stored at $-20^{\circ} \mathrm{C}$ at Common Research Laboratory (CRL). Serum copeptin levels were analyzed by ELISA (My BioSource, Cat.No: MBS044664) according to the manufacture's protocol. Both Intra-assay CV (\%) and Inter-assay CV (\%) were less than 15\%. hsCRP levels were measured using ELISA (Drg ${ }^{\oplus}$ Crp, Hs (C-Reactive Protein): Eia-3954). Inter-assay CV (\%) was less than $20 \%$.

\section{Statistical Analysis of Data}

The data was analyzed by SPSS 16.0 version software. Normally distributed variables were expressed as mean $\pm S D$ and non-normally distributed variables were expressed as median (IQR). Median values of the groups were compared with Mann-Whitney $\mathrm{U}$ test. $\mathrm{P}$ value less than 0.05 was considered as statistically significant.

\section{RESULTS}

Serum copeptin level of the whole study group was ranged from 1.49 to $15.95 \mathrm{pmol} / \mathrm{L}$ and its median value was $5.43 \mathrm{pmol} / \mathrm{L}$ with the interquartile range of $4.24-7.76$. Out of 87 subjects, 29 subjects $(33.33 \%)$ had the copeptin value $<5 \mathrm{pmol} / \mathrm{L}$. The median and interquartile range of that group was $3.56 \mathrm{pmol} / \mathrm{L}$ (2.69-4.28). The remaining 58 subjects (66.67\%) had the copeptin value $\geq 5 \mathrm{pmol} / \mathrm{L}$. The median and interquartile range in that group was $6.95 \mathrm{pmol} / \mathrm{L}$ (5.43-8.65) (Figure 1). Weight, BMI and waist circumference were significantly higher in centrally obese with high copeptin than those with low copeptin (Table 1).

Correlation between copeptin level and BMI was significant in the group including all study participants and in the group containing centrally obese with high copeptin (Figure 2 and 3). Copeptin level and waist circumference were also significantly correlated in the group of all study participants and centrally obese with high copeptin (Figure 4 and 5).

Median and interquartile range of hs-CRP in centrally obese with low copeptin level was $2.86 \mathrm{mg} / \mathrm{L}$ (1.63-6.7). Median and interquartile range of hs-CRP in centrally obese with high copeptin level was $3.42 \mathrm{mg} / \mathrm{L}$ (2.44-5.46). Significant difference in median values of hs-CRP was not found between these two groups $(\mathrm{P}=0.7)$ (Figure 6).

Table 1: Comparison of anthropometric measurements between centrally obese with high copeptin level and those with low copeptin level.

\begin{tabular}{cccc} 
Parameters & $\begin{array}{c}\text { Centrally obese with } \\
\text { low copeptin } \\
(<5 \text { pmol/L) } \\
(\mathbf{n}=29)\end{array}$ & $\begin{array}{c}\text { Centrally obese with } \\
\text { high copeptin } \\
(\geq 5 \text { pmol/L) } \\
(\mathbf{n}=58)\end{array}$ & P \\
\hline Age & $48.72 \pm 8.06$ & $47.31 \pm 7.47$ & 0.305 \\
Height & $161.07 \pm 5.36$ & $163.28 \pm 6.83$ & 0.374 \\
Weight & $70.21 \pm 5.95$ & $76.29 \pm 9.27$ & 0.016 \\
BMI (kg/m2) & $27.02 \pm 1.30$ & $28.56 \pm 2.62$ & 0.004 \\
$\quad$ Waist & $95.05 \pm 4.07$ & $98.22 \pm 6.80$ & 0.023 \\
circumference \\
$(\mathrm{cm})$
\end{tabular}

Data was expressed as mean \pm SD. $\mathrm{P}<0.05$ was considered as statistically significant. Comparison was done by unpaired $t$ test. BMI: Body mass index.

\section{DISCUSSION}

Serum copeptin level of the whole study group was ranged from 1.49 to $15.95 \mathrm{pmol} / \mathrm{L}$ and its median value was $5.43 \mathrm{pmol} / \mathrm{L}$ with the interquartile range of 4.24-7.76. Meanwhile the normal value or normal range for serum copeptin level has not yet been defined. However, there were many researchers studying serum copeptin level in healthy persons. In these studies, copeptin levels ranged from $1.0 \mathrm{pmol} / \mathrm{L}$ to $13.8 \mathrm{pmol} / \mathrm{L}$ with median copeptin value of $4.2 \mathrm{pmol} / \mathrm{L},{ }^{[6]}$ from 2.22 to $16.6 \mathrm{pmol} / \mathrm{L}$ with the median value $5.08 \mathrm{pmol} / \mathrm{L}^{[7]}$ and from 1.6 to $14.7 \mathrm{pmol} / \mathrm{L}$ with the median copeptin value $4.7(2.9-7.6)^{[8]}$ respectively. Moreover, in a review, copeptin levels in healthy volunteers ranged between 1 and $12 \mathrm{pmol} / \mathrm{L}$ with median values $<5 \mathrm{pmol} / \mathrm{L}$. ${ }^{[1]}$ Thus, 29 out of 87 subjects $(33.33 \%)$ having the copeptin value $<5 \mathrm{pmol} / \mathrm{L}$ were regarded as centrally obese with low copeptin level. The remaining 58 subjects (66.67\%) having the copeptin value $\geq 5 \mathrm{pmol} / \mathrm{L}$ were considered as centrally obese with high copeptin level.

In this study, copeptin level was significantly correlated with waist circumference and BMI in the whole study group and centrally obese

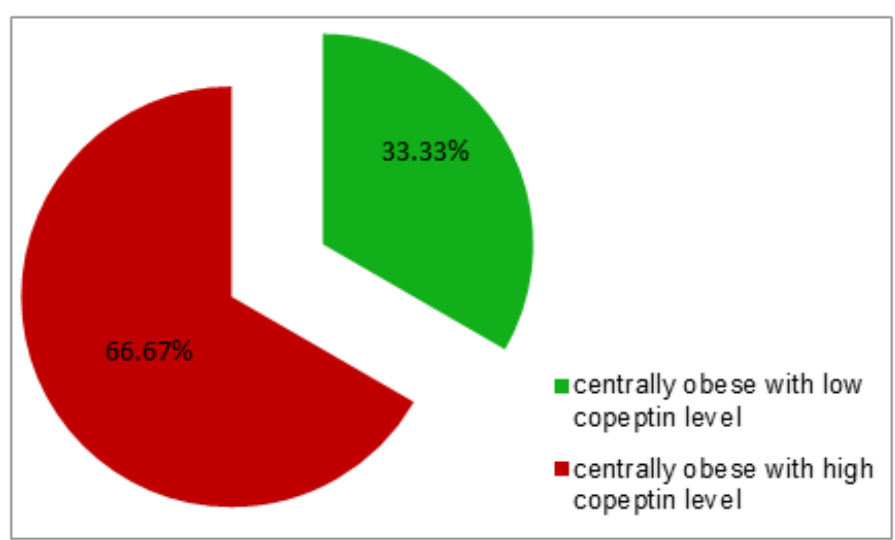

Figure 1: Distribution of centrally obese with high copeptin level and those with low copeptin level.

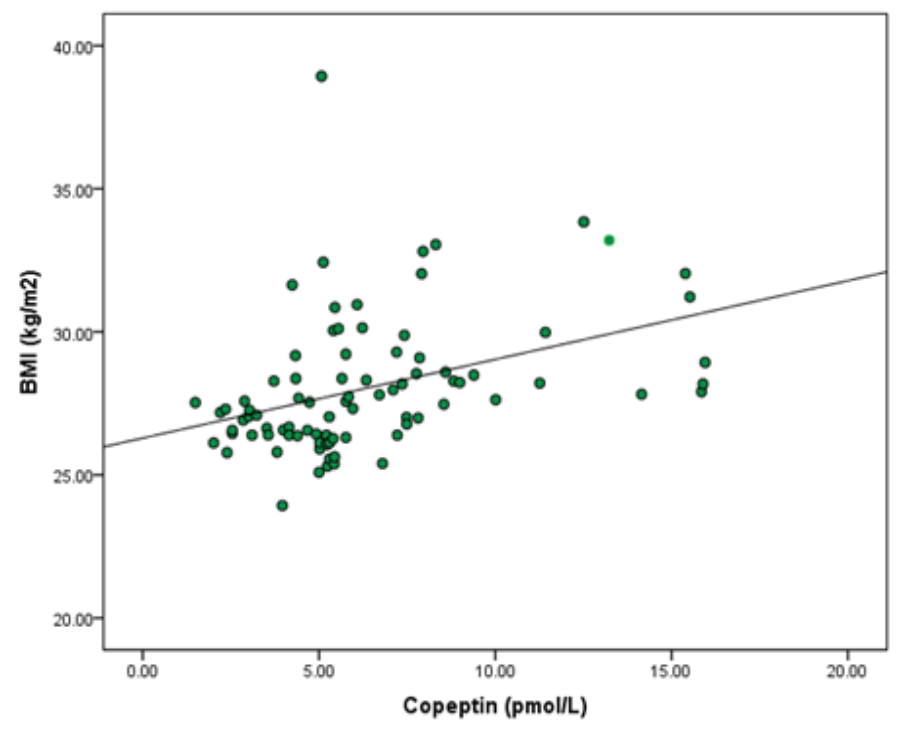

Figure 2: Correlation between copeptin and BMI in the whole group. Pearson Correlation $=0.31$; Correlation is significant at the 0.01 level BMI: Body mass index. 


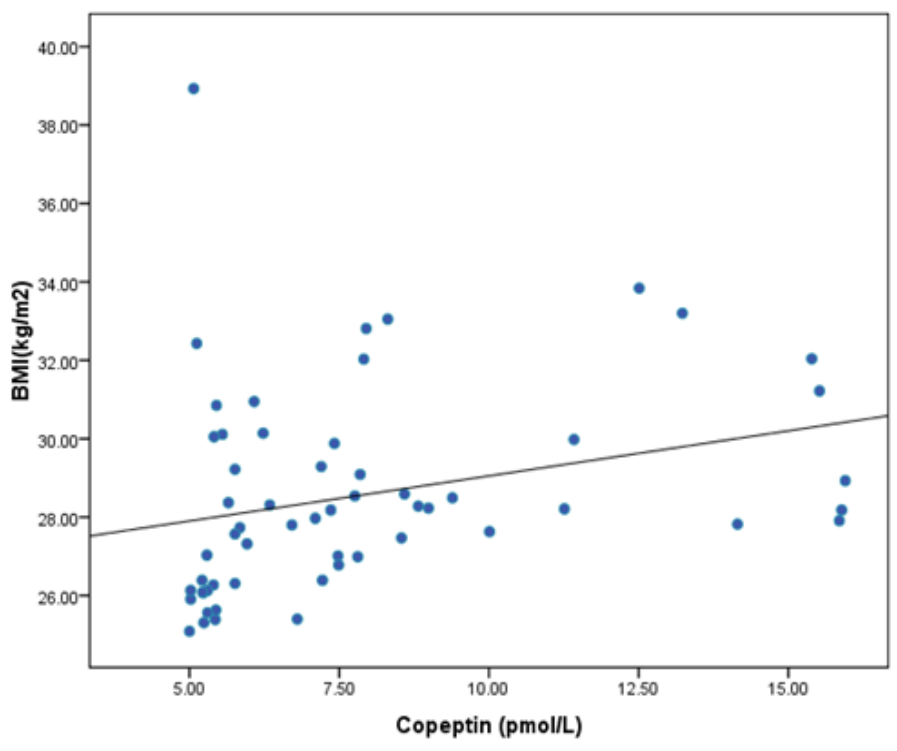

Figure 3: Correlation between copeptin and BMI in group of the centrally obese with high copeptin level.

Pearson Correlation $=0.28$; Correlation is significant at the 0.05 level BMI: Body mass index.

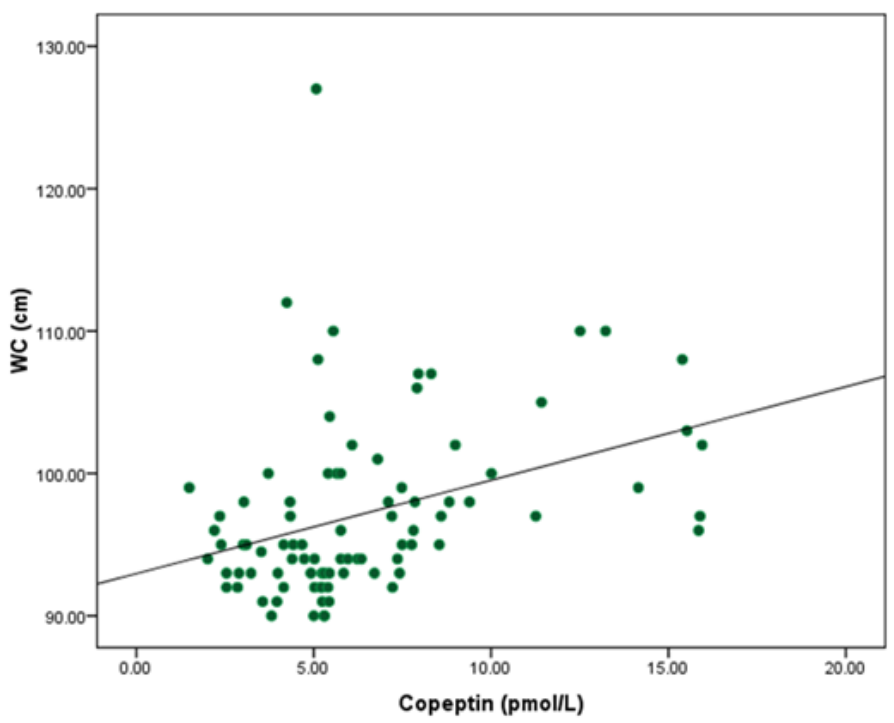

Figure 4: Correlation between copeptin and WC in the whole group. Pearson Correlation $=0.36$ and correlation is significant at the 0.01 level WC: Waist circumference.

with high copeptin level. Similarly, a study displayed significant correlation between copeptin level and BMI ( $\mathrm{p}<0.0095$, Rho 0.26) among 63 subjects having metabolic syndrome and mean age of 50.9 \pm 1.4 year. $^{[9]}$ In large population study of cohorts, copeptin was well associated with waist circumference (central obesity). ${ }^{[1]}$ Copeptin, a surrogate maker of vasopressin, is a marker of stress related HPA axis activation and consecutive rise in glucocorticoid. Therefore, the positive association of copeptin and waist circumference is due to the effects of hypercortisolism on adipocytes leading to central fat distribution and obesity. ${ }^{[1]}$

In the present study, the median hs-CRP value was $3.36 \mathrm{mg} / \mathrm{L}$ with the interquartile range of 2.26-5.71. Out of 87 subjects, 48 subjects (55.17\%)

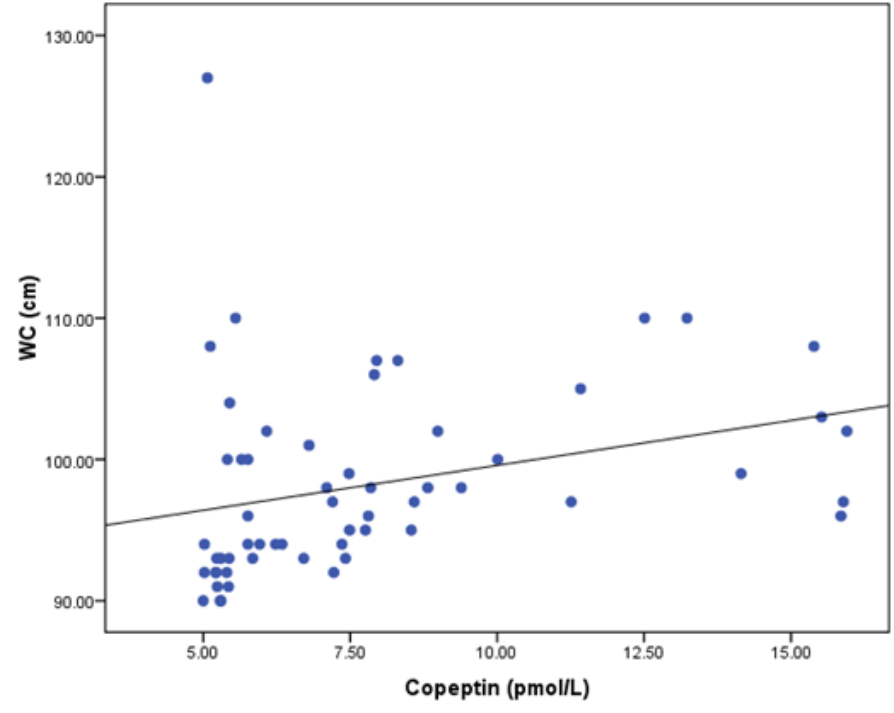

Figure 5: Correlation between copeptin and WC in group of the centrally obese with high copeptin level.

Pearson Correlation $=0.30$, correlation is significant at the 0.05 level

WC: Waist circumference.

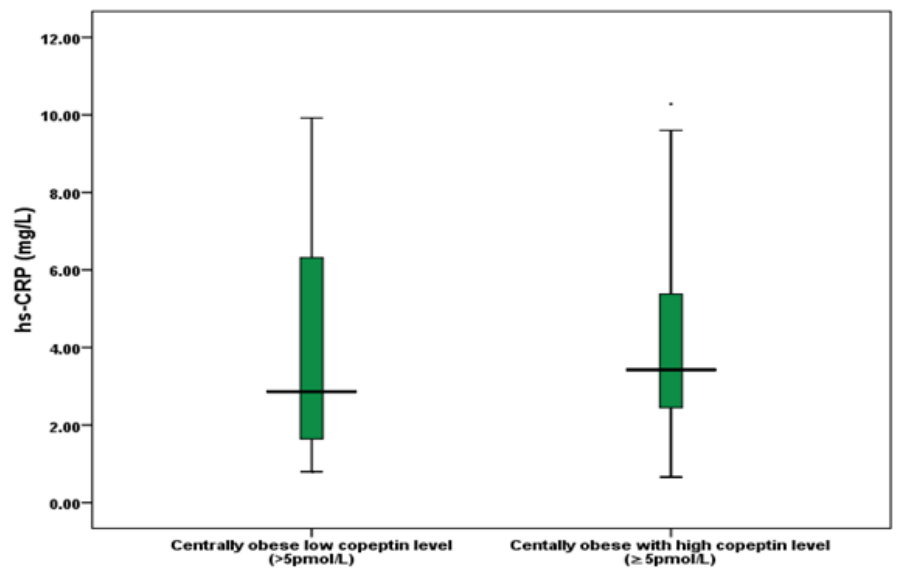

Figure 6: High sensitivity C-reactive protein level in low and high copeptin group.

Comparison was done by Mann-Whitney U test.

had hs-CRP level of more than $3 \mathrm{mg} / \mathrm{L}$ (high cardiovascular risk), hsCRP level of 35 subjects (40.23\%) was between 1 to $3 \mathrm{mg} / \mathrm{L}$ (moderate cardiovascular risk) and remaining only 4 subjects (4.6\%) had less than $1 \mathrm{mg} / \mathrm{L}$ of hs-CRP level (low cardiovascular risk) according to the American Heart Association and Centers for Disease Control and Prevention (AHA/CDC) (2003). Therefore, a large proportion of study population (95.4\%) had moderate to high cardiovascular risks with elevated level of hs-CRP ( $>1 \mathrm{mg} / \mathrm{L})$.

Median values of hs-CRP in centrally obese with low copeptin level and those with high copeptin level were $2.86 \mathrm{mg} / \mathrm{L}$ (1.63-6.7) and 3.42 $\mathrm{mg} / \mathrm{L}$ (2.44-5.46) respectively. Difference in hs-CRP levels failed to reach statistically significance $(\mathrm{p}=0.7)$. However, in the group of centrally obese with high copeptin level, there was higher percentage of participants having $>3 \mathrm{mg} / \mathrm{L}$ of hs-CRP level (58.62\%) comparing to those with low copeptin level (48.27\%). 
Contrary to the present study, a study reported that highly exhausted men due to job stress had significantly higher level of hs-CRP than nonexhausted men $(\mathrm{P}=0.008) \cdot{ }^{[10]}$ Other study exhibited that the caregivers had significantly elevated level of hs-CRP compared to control. ${ }^{[1]}$ These data pointed out that those suffering from chronic psychosocial stress displayed higher inflammatory status comparing to control.

In a cross sectional analysis of caregivers and controls, there was no significant difference in the two groups' hsCRP levels $(\mathrm{P}=0.44)^{[12]}$ Similarly, the male managers suffering from job stress (burnout) did not display significant difference in hsCRP level with control $(\mathrm{P}=0.37) \cdot{ }^{[13]}$ These data were compatible to the present study.

In a study caregivers who had no significant elevation in hsCRP at the start of study, exhibited significantly higher CRP levels $(\mathrm{P}=0.004)$ by the end of the 1-year study. ${ }^{[11]}$ At the same time, they displayed a linear decline in mRNA for anti-inflammatory signaling molecules. Similarly, few studies exhibited that duration of exposure to chronic stress had related to significance rise in hs-CRP. ${ }^{[12,14]}$ In accordance with these studies, duration of exposure to stress might effect on inflammatory status. An animal study also supported the importance of duration of chronic stress exposure on inflammation. ${ }^{[15]}$ In the present study, crosssectional study design could not support to explore the effect of duration of exposure to chronic stress on inflammatory status.

Furthermore, some studies showed that there was gender specific in inflammatory response to chronic stress. Only women, but not men, suffering from chronic stress due to caregiving had significantly higher hsCRP levels relative to control. ${ }^{[16,17]}$ Moreover, the study on male managers suffering from job stress (burnout) did not have significant difference in hsCRP level with control. ${ }^{[13]}$ On accounting to these findings, selection only on male subjects in the present study might be possible factor for failure to express significant difference between groups.According to the study by Steptoe A, et al. men showed greater TNF- $\alpha$ level after stress activity but women showed greater IL-6 level. ${ }^{[18]}$ The present study did not measure inflammatory cytokines such as TNF- $\alpha$ and IL-6. Yudkin et al. reported that hs-CRP could only reflect IL-6 level. ${ }^{[19]}$ Thus, in the present study, measuring hsCRP instead of TNF- $\alpha$ would be possible factor for lack of significant difference in hsCRP values between two groups.

\section{Limitations of the Study}

There were some limitations in the present study. In the present study, questionnaires were not used to assess chronic stress. Thus, this study should be reinforced by questionnaires because these questionnaires were well correlated with greater susceptibility to stress related illness in previous studies. Moreover, there are many stimuli for rising AVP or copeptin level. Although most of the confounding factors were excluded as much as possible, serum osmolality or urine flow rate was not be measured.

\section{CONCLUSION}

Though the impact of copeptin on inflammatory status could not be found in the present study, it should be reinforced with questionnaires for assessing their stress levels such as perceived stress scale, etc.

\section{CONFLICT OF INTEREST}

Authors declare that they have no conflict of interest.

\section{ABBREVIAITONS}

AVP: Arginine Vasopressin; SON: Supraoptic Nucleus; PVN: Paraventricular Nucleus; IL-6: Interleukin-6; TNF- $\alpha$ : Tumor Necrosis Factor alpha; BMI: Body Mass Index; WC: Waist Circumference.

\section{REFERENCES}

1. Enhörning S. The vasopressin system in diabetes mellitus, obesity and the metabolic syndrome. Hypertens Cardiovasc Dis. 2012.2.

2. Dobsa L, Edozien KC. Copeptin and its potential role in diagnosis and prognosis of various diseases. Biochemia Medica. 2012;23(2):172-90.

3. Scott KA. Melhorn SJ, Sakai RR. Effects of chronic social stress on obesity. Curr Obes Rep. 2012;1(1):16-25.

4. Garcia E, Aguilo S, Arza A, Garzin-Reya JM, Aguilo J. Psychological and physiological profiles in oncology caregivers: A Multivariable cross-sectional study. Mach Learn Artif Intell. 2017;5(4):547-57.

5. Chiang JJ, Eisenberger NI, Seeman TE, Taylor SE. Negative and competitive social interactions are related to heightened proinflammatory cytokine activity. Proc Natl Acad Sci U S A. 2012;109(6):1878-82.

6. Morgenthaler NG, Struck J, Alonso C, Bergmann A. Assay for the measurement of copeptin, a stable peptide derived from the precursor of vasopressin. Clin Chem. 2006;52(1):112-9.

7. Enhorning S, Bankir L, Bouby N, Struck J, Hedblas B, Persson M. Copeptin, a marker of vasopressin, in abdominal obesity, diabetes and microalbuminuria: The prospective Malmo Diet and Cancer Study cardiovascular cohort. Int J Obes. 2013;37(4):598-603.

8. Gastel M, Meijier E, Scheven LE, Struck J, Bakker SJ, Gansevoort RT. Modifiable factors associated with copeptin concentration: A general population Cohort. Am J Kidney Dis. 2015;65(5):719-27.

9. Vintilia M, Gheorghiu ML, Caragheorgheopol A, Baculescu N, Lichiardopol C, Badiu C. Increased copeptin levels in metabolic syndrome from a Romanian population. J Med life. 2016;9(4):353-7.

10. Wirtz PH, Kanel RV, Schnoepfeil P, Fischer J. Reduced glucocorticoid sensitivity of monocyte interleukin-6 production in male industrial employees who are vitally exhausted. Psychosom Med. 2003;65(4):672-8.

11. Rohleder N, Marrin TJ, Mo R, Miller GE. Biologic cost of caring for a cancer patient: Dysregulation of pro- and anti-inflammatory signaling pathways. J Clin Oncol. 2009;27(18):2909-15.

12. Kanel VR, Mills PJ, Mausbach BT, Dimsdale JE, Patterson TL, Ziegler MG. Effect of Alzheimer caregiving on circulating levels of $\mathrm{C}$-reactive protein and other biomarkers relevant to cardiovascular disease risk: A longitudinal study. J Gerontol. 2012;58(4):354-65.

13. Langelaan S, Bakker A, Schaufeli WB, Rhenen W. Is burnout related to allostatic load?. Int J Behav Med. 2007;14(4):213-21.

14. Janicki-Deverts D, Cohen S, Cullen MR. History of Unemployment predicts future elevations in $\mathrm{C}$ - reactive protein among male participants in the coronary artery risk development in young adults (CARDIA) study. Ann Behav Med. 2008;36(2):176-85.

15. Gutierrez-Coronado O, Gutierrez PTV, Villasenor-Garcia MM, Viveros-Parede $\mathrm{JM}$, Puebla-Perez AM. Activation of the hypothalamic- pituitary-adrenal axis induces the differential release of pro- inflammatory cytokines in BALB/C mice. Eur Sci J. 2015;11(27):367-80.16.

16. Toker S, Shirom A, Shapire I, Berliner S, Melamed S. The association between burnout, depression, anxiety, and inflammation biomarkers: C-reactive protein and fibrinogen in men and women. J Occup Health Psychol. 2005;10(4):344-62.

17. Shivpuri S, Gallo LC, Crouse JR, Alison MA. The association between chronic stress type and C-reactive protein in the multi-ethnic study of atherosclerosis (MESA): Does gender make a difference?. J Behav Med. 2012;35(1):74-85.

18. Steptoe A, Owen N, Kunz-Ebrecht S, Mohamed-Ali V. Inflammatory cytokines, socioeconomic status, and acute stress activity. Brain Behav Immun. 2002;16(6):774-84

19. Yudkin JS, Stehouwer CDA, Emeis JJ, Coppack SW. C-reactive protein in healthy subjects: Associations with obesity, insulin resistance, and endothelial dysfunction. Arterioscler Thromb Vasc Biol. 1999;19(4):972-8. 